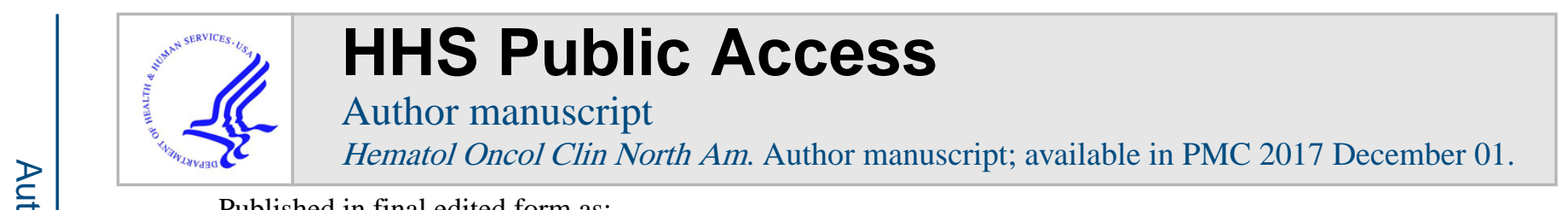

Published in final edited form as:

Hematol Oncol Clin North Am. 2016 December ; 30(6): 1293-1316. doi:10.1016/j.hoc.2016.07.013.

\title{
The Challenge of Primary CNS Lymphoma
}

\author{
Julia Carnevale, M.D. ${ }^{1}$ and James L. Rubenstein, M.D., Ph.D. ${ }^{1,2}$ \\ ${ }^{1}$ Division of Hematology/Oncology, University of California, San Francisco \\ ${ }^{2}$ Helen Diller Family Comprehensive Cancer Center, University of California, San Francisco
}

\begin{abstract}
Primary central nervous system lymphoma (PCNSL) represents one of the most challenging subtypes of aggressive non-Hodgkin's lymphoma, not only with respect to establishing the diagnosis, but also with respect to therapeutic resistance and treatment-related complications. Emerging clinical data suggest that optimized outcomes are achieved with dose-intensive central nervous system (CNS)-penetrant chemotherapy and the avoidance of whole brain radiotherapy. There is also increasing evidence that anti-CD20 antibody-based immunotherapy, incorporated as a component of high-dose methotrexate-based induction programs, may also contribute to improved outcomes. One of the interesting clinical questions in the present era is the determination of the optimal consolidative approach in the management of patients after remission induction therapy, with high-dose chemotherapy, minus or plus autologous stem cell transplantion, as well as reduced-dose whole brain radiotherapy representing the dominant therapeutic options currently under investigation. Additionally, an accumulation of insights into the molecular and cellular basis of disease pathogenesis is providing a foundation for the generation of molecular tools to facilitate diagnosis as well as a roadmap for integration of targeted therapy within the developing therapeutic armamentarium for this challenging brain tumor.
\end{abstract}

\section{Keywords}

Aggressive Lymphoma; Primary CNS Lymphoma; Brain Tumor; NF-kB; High-Dose Chemotherapy

\section{Introduction}

While PCNSL remains a rare neoplasm, representing only 2-3\% of all cases of nonHodgkin's lymphoma (NHL), the incidence of PCNSL among immunocompetent patients appears to be been increasing, particularly among persons age sixty-five years and older. ${ }^{1}$ The chararacteristic pathobiology of PCNSL is that of an aggressive lymphoma, localized

Corresponding Author: James L. Rubenstein, M.D., Ph.D. University of California, San Francisco, Division of Hematology/Oncology M1282 Box 1270 San Francisco, CA 94143 telephone 415-502-4430 Fax 415-476-0624 jamesr@medicine.ucsf.edu.

Disclosures: Dr. Rubenstein receives research funding from Genentech and Celgene.

Publisher's Disclaimer: This is a PDF file of an unedited manuscript that has been accepted for publication. As a service to our customers we are providing this early version of the manuscript. The manuscript will undergo copyediting, typesetting, and review of the resulting proof before it is published in its final citable form. Please note that during the production process errors may be discovered which could affect the content, and all legal disclaimers that apply to the journal pertain. 
within the central nervous system and often disseminated within brain, cranial nerves, leptomeninges, cerebrospinal fluid (CSF), intraocular structures and spinal cord, without overt systemic disease. ${ }^{2,3}$.

PCNSL has long been recognized to be an aggressive brain tumor associated with a poor prognosis. ${ }^{4}$ Historically known as reticulum cell sarcoma or microglioma, management principles for this disease have emerged slowly. Beginning in the 1960's, in the absence of prospective data, whole brain radiotherapy (WBRT) was employed as the first-line intervention as a means to elicit immediate responses in patients faced with a rapidly deteriorating course; WBRT alone typically resulted in median survival of 12 months. To date, the most significant advance in PCNSL has been the recognition, in the 1970's, of the efficacy of high-dose methotrexate (HD-MTX). ${ }^{5,6}$ Several recent prospective trials have demonstrated markedly improved outcomes in PCNSL. Our goal is to highlight significant advances in our understanding of disease biology, diagnosis, staging and therapeutic management. ${ }^{7-12}$

\section{Etiology}

Risk factors for PCNSL include acquired and/or congenital immunodeficiency states. PCNSL is an AIDS-defining illness associated with a low CD4 cell count $(<50$ cells $/ \mathrm{ml})$ and Epstein Barr Virus (EBV) infection. In systemic AIDS-related lymphomas, EBV infection of the lymphoma may be predictive of secondary CNS involvement. ${ }^{13}$ Congential immunodeficiency states such as Wiskott-Aldrich syndrome, severe-combined or commonvariable immunodeficiency, or ataxia-telangiectasia carry a $\sim 4 \%$ risk of PCNSL. Posttransplant lymphoproliferative disorder (PTLD) involving central nervous system develops in $1-2 \%$ of renal transplant recipients and $2-7 \%$ recipients of liver, cardiac, and lung transplants. CNS PTLD is associated with EBV in the setting of iatrogenic T-cell immunodeficiency induced by immunosuppressives such as mycophenolate mofetil (Cell Cept). ${ }^{14}$ Among patients with PCNSL without clinically overt immunosuppression, EBV infection of lymphoma is rare. ${ }^{15}$

\section{Clinical Features and Pathogenesis}

PCNSL is typically a highly infiltrative neoplasm that has been characterized as a "whole brain disease," particularly at relapse. ${ }^{16}$ For this reason, its radiographic appearance typically underestimates disease extent, and like malignant gliomas, PCNSL is not amenable to curative resection.. ${ }^{16}$ One of the archetypical histologic features of PCNSL is angiotropism; the accumulation of lymphoma cells around tumor vessels, a phenotype that likely disrupts the blood-brain barrier and enables radiographic detection of lesions via pathologic contrast enhancement. PCNSL commonly is diagnosed as a solitary mass, typically with vasogenic edema and mass effect. The frequency of multiple lesions is increased among the immunosuppressed. ${ }^{17}$ (Figure 1).

While NHL presenting in the brain is typically classified as PCNSL, subclinical tumorrelated clones are often detectable in the blood and bone marrow of PCNSL patients, suggesting that the brain microenvironment might promote malignant progression. ${ }^{18,19}$ 
Intraocular disease is a common manifestation: $20 \%$ of PCNSL patients present with involvement of the retina, uvea and vitreous. An important principle is that apparently localized intraocular lymphoma (IOL) will disseminate within brain in $>80 \%$ of cases; therefore, detection of IOL mandates staging of the neuroaxis. Therapies for IOL that address this risk should be strongly considered. ${ }^{20}$

Approximately 95\% of PCNSL are large B-cell lymphoma; other include T-cell $(2 \%)^{21}$, Burkitt, lymphoblastic, and marginal zone lymphomas. PCNSL is distinguished from duralbased marginal zone lymphomas as these rarely invade brain parenchyma and typically these share overlapping radiographic features on MRI with meningioma. ${ }^{22}$

\section{Molecular Pathogenesis of PCNSL}

Determination of the unique genetic features of PCNSL poses a greater challenge than for systemic DLBCL, both because of the rarity of this neoplasm and the paucity of material available for investigational studies. Most diagnostic specimens are obtained by stereotactic biopsy or via analysis of cerebrospinal fluid (CSF). Most investigations have focused on the elucidation of PCNSL, large cell type. Between 50\% to $80 \%$ of PCNSL express BCL6 by immunohistochemistry; ${ }^{23} 95 \%$ stain positive for MUM-1; therefore the majority of PCNSL cases are of a late germinal center or an activated B-cell immunophenotype. ${ }^{15}$ Immunohistochemical characterization of tumors from patients that participated in CALGB 50202 demonstrated that high BCL6 correlated with refractory disease and shorter progression-free and overall survival (Rubenstein et al., 2013b), thus representing a potentially useful molecular prognostic biomarker. While the adverse prognostic significance of high BCL-6 in PCNSL was recently confirmed in an independent large prospective trial, ${ }^{24}$ several small retrospective studies provided a conflicting result - that BCL-6 correlates with a better prognosis. This discrepancy raises the possibility that the prognostic significance of BCL-6 may be dependent upon treatment-related factors, such as rituximab or whole-brain radiotherapy. Between 56-93\% of PCNSL express BCL2. ${ }^{15,23}$

Transcriptional analyses of PCNSL identified several candidate mediators of disease pathogenesis, including expression of Pim 1 and $M Y C{ }^{2526}$ Increased MYC in PCNSL was confirmed in the recent CALGB 50202 study. ${ }^{12}$ Upregulation of miRNA's associated with MYC pathway (miR-17-5p, miR-20a, miR-9) has also been demonstrated. ${ }^{27}$ Circulating extracellular microRNA's in CSF such as miR-21 were also recently described in PCNSL, suggesting utility as clinical biomarkers. ${ }^{28}$

Given that aberrant somatic hypermutation contributes to the pathobiology of DLBCL, Montesinos-Rongen et al. evaluated the potential role of this mechanism in PCNSL. Somatic hypermutation of four proto-oncogenes was identified - PAX5, PIM1, c-MYC, and RhoH/ $T T F$, genes that regulate B cell development, proliferation and apoptosis ${ }^{29}$. Mutational frequencies for these were 2- to 5-fold higher in PCNSL compared to extraneural DLBCL ${ }^{29}$. Such high mutation frequencies suggest a prolonged interaction of the tumor cell in the GC microenvironment ${ }^{30}$. Whole exome sequencing studies of PCNSL identified protein-coding mutations involving mediators of cell signaling, CARD14, CD79A/B, TLR2, 
TLR6, and TLR10, regulators of cell cycle, CCND3, and CDK20, and chromatin structure CREBBP, MLL2, ARID1A/B, and SMARCA4.. ${ }^{31}$

The $p 16^{I N K 4 a}$ gene is commonly inactivated by either homozygous deletion (40-50\%) or $5^{\prime}$ CpG hypermethylation (15-30\%) in PCNSL. ${ }^{32}$ Inactivation of $p 14^{A R F}$ and $p 16^{I N K 4 a}$ genes by homozygous deletion or promoter hypermethylation may represent an important step in the molecular pathogenesis of PCNSL. The $p 14^{A R F}$ gene normally induces growth arrest and stabilizes p53 protein in the nucleus. Both $p 14^{A R F}$ and $p 16^{I N K 4 a}$ genes are frequently co-deleted; moreover, mice lacking the murine homologue of $p 14^{A R F}$ develop a variety of tumors, including lymphomas, sarcomas and gliomas. ${ }^{20,33,34,35}$ In contrast, mutations in the TP53 gene have been observed in only a small proportion of PCNSL.

Comparative genomic hybridization has identified other genetic lesions in PCNSL. Recurrent gains have been detected on chromosome 12 as well as on the long arms of chromosomes 1, 7, and 18; gain on chromosome 12 appears to be the most common chromosomal alteration, specifically in the 12q region harboring STAT6, MDM2, CDK4 and GLI1 ${ }^{20,34,36}$.

Another common genomic aberrational hotspot in PCNSL involves losses on chromosome 6p21 that harbor loci for HLA ${ }^{37-39}$ as well as broad deletions involving chromosome 6q. Chromosome 6q deletions, in particular 6q21-23 may be most frequent and occur in 40\%$60 \%$ of PCNSL. ${ }^{40}$ Candidate tumor suppressors linked to chromosome $6 \mathrm{q}$ include PRDM1, a tumor suppressor and regulator of B-cell differentiation, ${ }^{41} P T P R K$, a protein tyrosine phosphatase that participates in cell adhesion signaling events, ${ }^{42}$ and $A 20$ (TNFAIP3), a negative regulator of NFkB signaling. ${ }^{43}$

Further evidence for the aberrant activation of NFkB pathways in PCNSL is supported by a gain in DNA copy number for $M A L T 1^{44}$ as well as activating mutations of $C A R D 11^{45}$ and MyD88. The activating exchange of leucine to proline at position 265 of MyD88 may be enriched in PCNSL and has been demonstrated to occur in between $38 \%$ to $50 \%$ of cases. ${ }^{46,47}$ (Figure 2).

Several lines of investigation support a role for JAK/STAT signaling pathway as a mediator of pro-survival signals in PCNSL. Interleukin-4, a B-cell growth factor that mediates intracellular signals via JAK/STAT, is upregulated at the transcript and protein level within the vascular microenvironment in PCNSL tumors. ${ }^{25}$ Increased concentration of IL-10 (another activator of JAK/STAT) is detectable in the vitreous and CSF in PCNSL and, in independent studies, correlated with adverse prognosis. ${ }^{48,49} \mathrm{~A}$ recent analysis demonstrated upregulated IL-10 transcripts in primary CNS lymphoma tumors compared to secondary CNS lymphomas and nodal lymphomas, with concomitant upregulated IL-10 protein in CSF from cases of PCNSL. In addition, CSF concentration of IL-10 correlated with tumor response and progression in patients treated with rituximab and methotrexate. ${ }^{50}$ Finally, intratumoral JAK1 transcripts are upregulated in PCNSL. ${ }^{25,51}$ Importantly, elevated IL-10 expression plus activation of JAK/STAT signaling in PCNSL are manifestations of aberrant activation of the MyD88 pathway. ${ }^{52}$ (Figure 2-4). 
In addition, $C D 79 B$, a component of the B-cell receptor signaling pathway, is mutated in approximately $20 \%$ of cases, providing further data that dysregulation of the B-cell receptor and the NFkB signaling pathway contribute to pathogenesis of PCNSL. ${ }^{53}$ (Figure 2) Silencing of $C D K N 2 A$, a cell cycle regulator, occurs in $50 \%$ of cases and is linked to inferior outcome. ${ }^{44,46}$

\section{Tumor Microenvironment in PCNSL}

The molecular basis for tropism and selective dissemination of lymphoma within the brain are problems that are fundamental to the pathogenesis of PCNSL. In vitro chemotactic responses by large B-cell lymphoma cells isolated from brain lesions have been demonstrated in response to chemokines CXCL12 (SDF-1) and CXCL-13 (B-lymphocyte chemoattractant) have been demonstrated ${ }^{54-56}$ providing evidence for their role as neurotropic factors. Moreover, high CXCL-13 concentration in CSF from CNS lymphoma patients correlates with adverse prognosis, supporting its role as a pro-survival factor in PCNSL. In addition, determination of the CSF concentration of CXCL-13, as well as IL-10, facilitate diagnosis of CNS lymphoma in that bivariate expression of each molecule has diagnostic sensitivity at least two-fold greater than cytology or flow-cytometry. In a multicenter investigation, the positive predictive value of bivariate elevation of IL-10 plus CXCL-13 in CSF was 95\% in the identification of untreated PCNSL. ${ }^{50}$

Given that expression of B-cell chemokines CXCL13 and SDF-1 by retinal pigment epithelium has also been demonstrated in primary intraocular lymphomas, these chemokines may also contribute to lymphoma cell homing to the retinal pigment epithelium from choroidal circulation 57

While under physiologic conditions, the brain is believed to be immunologically quiescent, diagnostic specimens of PCNSL often reveal a robust inflammatory response, with infiltrating reactive T-cells and activated macrophages. Notably, perivascular T-cell infiltrates in PCNSL may predict a favorable outcome, suggesting that immunotherapeutic interventions that potentiate T-cell-mediated immune surveillance may be effective. ${ }^{58}$

\section{Diagnostic Evaluation of the Patient with a Focal Brain Lesion}

Because patients with PCNSL/IOL commonly present with a variety of nonspecific and/or subtle neurologic symptoms, the diagnostic process may be protracted and extend for months-to-years. (Figure 5). The cornerstone of diagnostic testing in suspected PCNSL is MRI of the brain, with gadolinium contrast. In 95\% of PCNSL, pathologic enhancement localizes homogeneously to dominant lesions. Among the immunocompetent, lesions are solitary in $65 \%$ of PCNSL patients and multifocal in 35\%. Involvement of the cerebral hemispheres is most common (38\%) followed by thalamus and basal ganglia (16\%), corpus callosum (14\%) periventricular loci (12\%) and cerebellum (9\%). ${ }^{59}$.

While there is insufficient data to recommend newer techniques such as quantitative diffusion-weighted and perfusion MRI as "standard of care," an accumulation of recent data demonstrates the utility of these metrics in prognostication as well as diagnosis of CNS lymphomas and related inflammatory and malignant conditions. ${ }^{10,60-65}$ Given the 
quantitative nature of these techniques, and their universal availability in standard MRneuroimaging packages, it is possible that these will be incorporated in future studies.

Although glucocorticoids typically induce radiographic regressions in $>40 \%$ of patients, steroid-induced responses also increase risk of a non-diagnostic vitreal or brain biopsy. ${ }^{66}$ Steroid-induced diagnostic delays may extend for months, and on occasion, steroid-induced regressions of sentinel lesions may delay diagnosis of PCNSL or IOL for years. ${ }^{67}$ It is therefore important to emphasize that empiric glucocorticoids such as dexamethasone be tapered rapidly, or not administered until a diagnosis is established.

The standard diagnostic approach for PCNSL is stereotactic brain biopsy; in selected cases, a subtotal resection may be appropriate if deemed to be safe. Flow-cytometric or cytologic analysis of meningeal lymphoma cells isolated from CSF or vitrectomy may also yield the diagnosis. Notably, while flow-cytometry has increased diagnostic yield relative to cytology, CSF needs to be efficiently processed for studies designed to identify, in most cases, a kappa or lambda-restricted B-cell lymphoma. Repeat CSF cytological or flow-cytometric studies infrequently improve diagnostic yield, supporting development of innovative diagnostic methods based upon detection of genomic aberrations such as detection of oncogenic alleles of MYD88. ${ }^{68}$

Given that approximately $80 \%$ of patients with IOL will exhibit CNS dissemination, MRI of the brain with gadolinium may be indicated in the work-up of idiopathic uveitis in which lymphoma is a diagnostic consideration. Additional staging tests for IOL include fluorescence angiography and optical coherent tomography, as well as evaluation of mutant L265P MYD88 ${ }^{68}$; intraocular concentrations of the cytokines IL-10 and IL-6 may also be useful adjuncts to diagnosis. ${ }^{69}$

Staging evaluation for the patient with presumptive PCNSL includes complete ophthalmologic examination plus systemic staging via computed tomography of chest, abdomen and pelvis plus bone marrow biopsy; the value of positron emission tomography in staging of PCNSL is not established. ${ }^{70}$ but may be useful in possible concomitant testicular involvement in men older than 60 .

\section{Clinical Prognostic Determinants in PCNSL}

The International Extranodal Lymphoma Study Group (IELSG) identified five clinical variables that correlate with prognosis in PCNSL, three are shared with systemic NHL: elevated LDH, age > 60, and performance status > 1; parameters specific to PCNSL include elevated CSF protein as well as tumor location within the deep regions of the brain (periventricular, basal ganglia, brainstem and/or cerebellum). The presence of $0-1,2-3$, or $4-5$ adverse risk factors respectively correlates with 2 -year survival rates of $80 \%, 48 \%$ or $15 \% .^{71}$ Historically, age has been the most reliable clinical prognostic factor, however there is disagreement regarding the age cut-point at which prognosis declines. While IELSG considers age 60 years to be the cutpoint above which prognosis declines, the Memorial Sloan-Kettering (MSK) prognostic index uses a cutpoint of age 50. ${ }^{72}$ Notably, in CALGB 50202, which evaluated intensive immunochemotherapy followed by high-dose 
consolidation, without WBRT, outcomes for PCNSL patients older than 60 was similar to younger patients, a result that suggests that the optimal cutpoint for age as a prognostic variable is strongly linked to the effects of delayed neurotoxicity. ${ }^{12 ; 10}$ (Figure 6).

\section{Principles of Management in PCNSL}

\section{Surgery: Biopsy vs. Resection}

Many authorities recommend against neurosurgical resection of PCNSL, given the scant evidence that surgical cytoreduction provides no survival benefit and increases risk of postoperative neurologic deficit. ${ }^{73,74}$ On the other hand, data extracted from the German PCNSL SG-1 Trial provided evidence that aggressive resection of PCNSL correlated with improved PFS. ${ }^{75}$ In many cases, maximum safe resection of lesions provides immediate relief of mass effect, facilitates glucocorticoid taper, and theoretically eliminates drug-resistant tumor clones, without contributing to neurologic deficits, particularly when performed using modern neurosurgical mapping techniques.

\section{Whole Brain Irradiation (WBRT) in PCNSL}

The positive impact of WBRT in PCNSL is compromised by at least three important shortcomings: (1) Inadequate local control of lymphoma; (2) Subclinical dissemination of radiographically-occult lymphoma cells outside of the radiation field; (3) Deleterious delayed effects of radiation on normal brain function. In one study, the use of WBRT as the sole intervention in PCNSL yielded a median survival of only 11.6 months, and greater than $60 \%$ of patients experienced lymphoma progression within the irradiated field. ${ }^{76}$ The archetypical features of the delayed neurotoxicity of WBRT in PCNSL include incontinence, gait and memory disturbances - toxicities that are most evident in patients older than 60; PCNSL survivors that experience late-delayed neurotoxicity of WBRT may ultimately require custodial care. ${ }^{77}$ While lower doses of WBRT were associated with neurotoxicity that is barely discernable in preliminary studies, ${ }^{78}$ additional validation of these results are necessary, and need to be reconciled with the established deleterious neurocognitive effects of prophylactic cranial irradiation at $30 \mathrm{~Gy},{ }^{79}$. It seems plausible that the neurotoxicity of WBRT is a continuous variable in terms of its relationship to dose. Importantly, it was recently noted that PCNSL patients older than 60 that received consolidative low-dose WBRT (23.4 Gy) experienced inferior outcome in terms of progression-free survival (PFS) compared to patients younger than $60 .{ }^{80}$ Given the rising incidence in PCNSL in older patients, these results substantiate the need for innovative strategies that defer or eliminate WBRT as therapy in PCNSL.

\section{Induction Chemotherapeutic Strategies in PCNSL}

The feasibility and efficacy of high-dose methotrexate in CNS lymphomas was established in the 1970's 5,6 and led to its incorporation more broadly in induction and salvage regimens. High-dose methotrexate has been identified in multivariate analysis as the most important treatment-related prognostic variable related to survival in CNS lymphomas. ${ }^{81}$.

While the optimal dose of methotrexate has not been defined, systemic doses $\geq 1 \mathrm{gm} / \mathrm{m}^{2}$ mediate lymphocytotoxic effects within brain parenchyma. ${ }^{6}$. In a landmark study, Glantz 
and colleagues demonstrated that intravenous methotrexate administered at $8 \mathrm{~g} / \mathrm{m}^{2}$ over four hours yielded higher cytotoxic levels of methotrexate in serum and CSF compared to intrathecal methotrexate $(12 \mathrm{mg})$ at 48 and 72 hours. ${ }^{82}$ Also, investigators at Memorial Sloan-Kettering Cancer Center demonstrated that elimination of intrathecal methotrexate during initial therapy for PCNSL did not affect outcome in patients receiving high-dose methotrexate at doses of at least $3.5 \mathrm{gm} / \mathrm{m}^{2.83}$ In summary, these studies indicate that highdose intravenous methotrexate, administered every two weeks for a minimum of six cycles, can be used to treat large cell lymphoma within brain and leptomeningeal compartments, without intrathecal therapy. ${ }^{10}$

\section{Prevention and Management of High-Dose Methotrexate Toxicity}

The principal toxicity of high-dose methotrexate is nephropathy, caused by precipitation of methotrexate and its metabolite 7-OH methotrexate within renal tubules. Measures to prevent this life-threatening complication include hydration, urine alkalinization and avoidance of drugs that interact with MTX such as pencilillins, as well as drainage of third space effusions. Additional interventions for delayed methotrexate clearance include carboxypeptidase-G2 (CPDG2, glucarpidase) a recombinant enzyme that rapidly reduces toxic serum methotrexate, via direct hydrolysis of methotrexate $;{ }^{84}$ glucarpidase was approved by the FDA in 2012 .

\section{Combined-Modality Regimens}

Combined modality therapy was pioneered at Memorial Sloan-Kettering Cancer Center and consisted of HD-MTX plus procarbazine and vincristine, followed by WBRT and high-dose cytarabine. Evaluation of this approach in a multicenter RTOG trial demonstrated median PFS of 24 months. ${ }^{85}$. Because of this encouraging efficacy, combined-modality therapy became a widely adopted approach for PCNSL. ${ }^{86,87}$ In a multicenter randomized phase II study, Ferreri evaluated HD-MTX-based induction, minus or plus high-dose cytarabine followed by consolidative WBRT: the median failure-free survival in patients receiving HDAra-C in combination with HD-MTX was eight months; in contrast, median failure-free survival for patients treated with HD-MTX without cytarabine was only four months (Ferreri et al., 2009). In the SG-1 randomized trial involving 551 PCNSL patients in which half received WBRT as first-line consolidation, Thiel and colleagues provided evidence that omission of WBRT from first-line treatment did not impact overall survival. While the study revealed a modest effect of WBRT on PFS after methotrexate-based induction, this did not translate into improved overall survival, possibly attributable to the neurotoxicity detected in the radiotherapy arm. ${ }^{88}$

\section{Alternatives to WBRT Consolidation: High-Dose Chemotherapy}

Given the recognition of inadequate efficacy as well as neurotoxicity associated with WBRT, there has been interest in development of strategies that eliminate radiotherapy. One approach has been high-dose chemotherapeutic consolidation, including autologous stem cell transplant (ASCT). Regimens that contain CNS penetrant agents such as carmustine, thiotepa, cyclophosphamide, busulfan, high-dose cytarabine and etoposide are associated with the best results. However, in one early trial, results using the BEAM combination (carmustine, etoposide, cytarabine and melphalan) followed by autologous stem cell rescue 
were not encouraging, possibly because a major proportion of patients enrolled in the study had inadequate disease control before myeloablative therapy, likely because of the abbreviated course of high-dose methotrexate administered. ${ }^{89}$

Soussain and colleagues evaluated dose-intensive chemotherapy and autologous stem cell transplant in recurrent CNS lymphomas and IOL. These investigators noted that combination high-dose cytarabine plus etoposide constituted a highly potent salvage regimen for relapsed/refractory CNS lymphomas: 12 of 14 patients attained responses, 8 of which were complete. Responding patients received a myeloablative regimen consisting of thiotepa, busulfan and cyclophosphamide (TBC) followed by stem cell rescue. ${ }^{90}$

Beginning in 2001, investigators at the University of California, San Francisco (UCSF), began to evaluate dose-intensive chemotherapy in first-line consolidation, without WBRT, after induction immunochemotherapy with rituximab in newly-diagnosed PCNSL. The strategy involved a two-step regimen: the induction phase uses HD-MTX given every two weeks with temozolomide and rituximab (MT-R). Intravenous rituximab is administered starting day 3 , and weekly for six infusions, an interval during which the blood-brain barrier may be most compromised by angiotropic lymphoma. ${ }^{91}$ Temozolomide is a lipophilic alkylating agent with activity at relapse in CNS lymphoma, alone and in combination with rituximab ${ }^{92-94}$. Temozolomide yields superior health-related quality of life and toxicity characteristics compared to procarbazine in brain tumor patients ${ }^{95,96}$. To consolidate response after induction MT-R, PCNSL patients received intensive consolidation with noncross-resistant agents with combination "EA": 96-hour infusional etoposide plus eight doses of cytarabine at $2 \mathrm{gm} / \mathrm{m}^{2.97-99}$. Notably, infusional etoposide is incorporated within the EPOCH regimen (etoposide, doxorubicin, cyclophosphamide, vincristine and prednisone), highly effective in large B-cell lymphoma ${ }^{100,101}$. Etoposide has demonstrated efficacy in brain tumours, including CNS lymphoid leukemia ${ }^{102}$. Notably, when given with CHOP in patients with aggressive lymphoma, etoposide was associated with a reduced risk of secondary CNS lymphoma. ${ }^{103}$

A key goal of the two-step MT-R EA program was to develop an induction regimen that incorporates an alkylator, temozolomide ${ }^{93}$ as well as rituximab ${ }^{104}$, and yet causes minimal myelosuppression, to enable minimal treatment delays during the first weeks of treatment, the interval at which maximal lymphoma cytoreduction is achieved. Long-term follow-up of the first cohort of PCNSL patients treated with this regimen demonstrates that combination EA is highly effective as consolidation after MT-R in newly diagnosed PCNSL. ${ }^{10}$ Based on phase I data, the MT-R plus EA regimen was evaluated in CALGB 50202, demonstrating for the first time the feasibility of high-dose chemotherapy in a multicenter study in newlydiagnosed PCNSL. The rate of complete response to MT-R in CALGB 50202 was $66 \%$ and the two-year PFS was 59\%. Median time to progression of all 50202 patients, four years, is two-times longer than achieved with combined-modality therapy in multicenter trials using standard-dose WBRT and may be similar to or favorable to results of reduced-dose WBRT in patients older than $60 .{ }^{85,88}$ Other key findings from CALGB 50202 were that outcomes were similar for PCNSL patients older than 60 compared to younger patients and the observation that the PFS curves reached a stable plateau, supporting the hypothesis that long-term survival can be achieved in PCNSL without brain irradiation. 
Given the encouraging results of CALGB 50202, a successor, randomized phase II trial, CALGB 51101, has been activated in the United States, endorsed by the major cooperative groups: Alliance, ECOG and SWOG. In CALGB 51101 after randomization and remission induction therapy with MT-R, patients receive either consolidation with EA or myeloablative therapy with carmustine plus thiotepa. ${ }^{7}$

The myeloablative approach pioneered by Soussain et al. using the TBC conditioning regimen in relapsed CNS lymphoma was also recently evaluated in a phase II investigation performed at Memorial Sloan-Kettering for PCNSL in which newly-diagnosed PCNSL patients that responded to induction chemotherapy consisting of rituximab, high-dose methotrexate plus procarbazine and vincristine received consolidative TBC chemotherapy. Results of this investigation were highly promising with a two-year PFS of 79\%, however treatment-related mortality among transplanted patients that received the TBC conditioning regimen was substantial: $11.5 \%{ }^{105}$

\section{Alternatives to WBRT: Induction HD-MTX Therapy without Consolidation in Elderly Patients with PCNSL}

Given the established toxicities of WBRT, as well as concerns regarding the feasibility of high-dose chemotherapy consolidation in patients older than 60 , one approach has been to apply methotrexate-based induction regimens for newly-diagnosed elderly patients and to withhold consolidation, reserving salvage chemotherapy or radiation for disease progression. Results of a recent European intergroup, randomized phase II trial evaluated two promising methotrexate-based regimens - high-dose methotrexate $(3.5 \mathrm{gm} / \mathrm{m} 2)$ plus temozolomide vs. high-dose methotrexate $(3.5 \mathrm{gm} / \mathrm{m} 2)$ plus procarbazine, vincristine and high-dose cytarabine; neither regimen included radiotherapy. Remarkably the 1-year PFS, (the primary endpoint) was the same with both regimens, $36 \%$ there was however, a small, but statistically insignificant, trend for improved overall survival in patients that received the four drug regimen that contains high-dose cytarabine. ${ }^{106}$

\section{Neurocognitive Function}

Given the recent progress in outcomes in PCNSL, the consequences of treatment-related neurotoxicity among survivors has emerged as an increasingly important question. While reduced-dose brain radiotherapy may be associated with milder cognitive dysfunction among PCNSL survivors compared to standard-dose WBRT, ${ }^{78}$, even reduced doses of WBRT as consolidation are associated with impairments of Verbal Memory and Motor Speed. By contrast, PCNSL patients treated with HD-MTX without consolidative WBRT do not exhibit severe cognitive dysfunction as determined by neuropsychological testing; PCNSL patients treated with HD-MTX without WBRT nevertheless score lower than normative control subjects in several domains including motor speed and executive function. ${ }^{107}$ Given that PCNSL is an infiltrative brain tumor associated with a spectrum of neurologic symptoms, determination of whether impairments of neurologic function are the consequence of lymphoma versus neurotoxicity of agents such as methotrexate remains a challenge. 


\section{Treatment of Recurrent PCNSL}

Several studies have demonstrated that dose-intensive chemotherapy with stem cell rescue can be an effective option in the treatment of relapsed CNS lymphomas and IOL. ${ }^{8,90,108}$ In the setting of recurrent disease that is methotrexate-sensitive, one approach is to administer additional cycles of HD-MTX, to achieve maximal cytoreduction, followed by doseintensive chemotherapy consolidation using non-cross-resistant, CNS penetrant agents such as thiotepa ${ }^{9,109,110}$ High-dose carmustine-based therapy without thiotepa has also been studied. ${ }^{111}$ (Table 1) For CNS lymphomas that have progressed within six months of doseintensive chemotherapeutic consolidation, salvage high-dose chemotherapy may not be an effective option. Such patients may be managed with additional HD-MTX, pemetrexed, ${ }^{112}$, WBRT or investigational agents in CNS lymphoma such as lenalidomide or ibrutinib.

\section{Rituximab in CNS lymphomas}

While rituximab has become a cornerstone of therapy in systemic B-cell NHL, a number of studies demonstrated that the addition of rituximab to CHOP may not significantly decrease the rate of CNS recurrence of systemic large B-cell lymphoma compared to CHOP alone. ${ }^{113-115}$ Nevertheless, intravenous rituximab can induce responses of contrastenhancing lesions in CNS lymphoma, likely in lesions in which there is substantial disruption of the blood-brain barrier. ${ }^{104}$ Further data substantiating the role for rituximab in PCNSL has recently been provided in a randomized phase II study led by Ferreri that evaluated the MATRIX regimen, comprised of a methotrexate/cytarabine backbone plus thiotepa and rituximab. Results presented at the 13th International Conference on Malignant Lymphoma, in June 2015 in Lugano, confirm significantly improved outcomes in PCNSL patients that received rituximab.

\section{Intraventricular Rituximab in CNS Lymphomas}

The safety and efficacy of intraventricular rituximab, both as monotherapy and in combination with intraventricular methotrexate was recently evaluated in the setting of two phase I multicenter trials involving patients with recurrent primary and secondary CNS lymphomas. ${ }^{26,116}$ These studies demonstrated that, when diluted in preservative-free normal saline and administered into ventricular CSF, 10 and $25 \mathrm{mg}$ doses of rituximab are welltolerated and elicited responses within leptomeninges, intraocular compartments and in small parenchymal lesions. The efficacy of intraventricular rituximab was additive or synergistic with methotrexate. One of the key findings was that intraventricular rituximab/ methotrexate was particularly active in patients with a high burden of leptomeningeal lymphoma. These studies also suggested that intraventricular rituximab overcomes the problem of the blood-brain barrier, in that CSF responses were documented in patients with baseline serum rituximab concentrations greater than $15 \mu \mathrm{g} / \mathrm{ml} .{ }^{26,116}$ A potential mechanistic explanation for the rapid efficacy of intraventricular rituximab is provided by activation of the complement cascade at $\mathrm{C} 3$ as well as the C5b-9 membrane attack complex within CSF upon intra-CSF rituximab administration. ${ }^{117}$

Given the evidence for activity of intravenous rituximab in CNS lymphomas, as monotherapy and in combination with methotrexate-based induction, ${ }^{118}$ a number of protocols now incorporate this anti-CD20 monoclonal antibody as a component of induction 
in PCNSL. While several studies demonstrate its activity at relapse, intraventricular rituximab remains investigational and the combination of intraventricular plus intravenous rituximab with lenalidomide for recurrent CNS lymphomas is currently being studied in phase I investigation (NCT01542918).

\section{Treatment of Intraocular Lymphoma (IOL)}

Most cases of IOL involve large B-cell NHL, and are classified as either primary vitreoretinal lymphoma or uveal lymphomas; these are divided into primary neoplasms of the choroid, iris and ciliary body, or secondary choroidal lymphomas in patients with systemic NHL. Importantly, between $65 \%$ to $90 \%$ of patients with primary vitreoretinal lymphoma (PVRL) ultimately disseminate throughout the neuroaxis, typically within 30 months. Conversely, IOL impacts $15-25 \%$ of patients with PCNSL.

Therapies for PVRL can be divided into local approaches such as ocular radiation or intravitreal therapy vs. systemic chemotherapy. External beam radiotherapy using opposed lateral beams to the eyes is well tolerated, and associated with low rates of local recurrence. Typical complications of ocular radiotherapy are mild and include dry eye, cataracts and radiation retinopathy ${ }^{119}$ Intravitreal methotrexate and rituximab may be of value in management of unilateral disease or in the setting of prior ocular radiation. ${ }^{120,121}$ Treatmentrelated complications of intravitreal methotrexate include hemorrhage, endophthalmitis, hypotnony and retinal detachment. ${ }^{122}$ Systemic therapeutic options for IOL include HDMTX, ${ }^{123}$ high-dose cytarabine or trofasfamide. ${ }^{124125}$ Notably, in PVRL, systemic HD-MTX plus binocular irradiation provides local disease control and addresses the probability of subclinical disease throughout the neuroaxis. ${ }^{126}$ Our approach to patients with primary IOL and/or concomitant PCNSL with IOL typically involves 3 steps: (1) HD-MTX--based induction (with rituximab, if disease is CD20+); (2) dose-intensive chemotherapeutic consolidation with EA or ASCT (3) Binocular radiotherapy, but not WBRT if there is persistence and/or recurrence of isolated IOL after completion of dose-intensive consolidation.

\section{PCNSL in the Immunocompromised Host}

While the incidence of HIV-associated PCNSL declined in incidence with advent of combination anti-retroviral therapy (cART), PCNSL remains a significant AIDS-defining illness that represents a major therapeutic challenge. Feasibility and efficacy of HD-MTX in HIV-associated PCNSL has been demonstrated. ${ }^{127}$ Similarly, in the setting of CNS posttransplant lymphoproliferative disorder (PTLD), reconstitution of immune function is a first principle, and is achieved by reduction in immunosuppression. HD-MTX is usually effective but its implementation needs to be balanced with risk of allograft failure. ${ }^{128}$ Rituximab is also active in the CNS complications of PTLD, via intravenous as well as intrathecal administration. ${ }^{129}$

\section{Conclusions and Future Directions}

Over the past 50 years, significant progress has been achieved in the treatment of PCNSL, an aggressive variant of large B-cell lymphoma. Between 40-50\% of PCNSL patients are now 
likely to exhibit long-term survival and a significant proportion may be cured. However given that at least $50 \%$ of patients develop disease refractory to the established armentarium of agents, it is now imperative that additional studies explore the potential efficacy of selective agents that target candidate resistance mechanisms in high-risk PCNSL patients. ${ }^{130}$ For example, pharmacologic agents that evaluate disruption of NF-kB activating pathways involving the B-cell receptor, toll-like receptor, and PIM kinases are high priority in early phase investigation in PCNSL. Another key target is MUM-1/IRF-4, targeted by IMiD small molecule agents such as lenalidomide, or CC-122, ${ }^{131}$ currently under evaluation in relapsed PCNSL 132,133 Transformative advances are needed given the predilection of PCNSL for an aging population that often cannot tolerate dose-intensive chemotherapy or WBRT.

\section{Acknowledgments}

Supported by the National Institutes of Health, University of California San Francisco-Gladstone Institute of Virology \& Immunology Center for AIDS Research (P30 AI027763), NIH R01CA139-83-01A1, and by the Leukemia \& Lymphoma Society (JLR).

\section{References}

1. Villano JL, Koshy M, Shaikh H, Dolecek TA, McCarthy BJ. Age, gender, and racial differences in incidence and survival in primary CNS lymphoma. Br J Cancer. 2011; 105:1414-1418. [PubMed: 21915121]

2. Hochberg FH, Miller DC. Primary central nervous system lymphoma. J Neurosurg. 1988; 68:835853. [PubMed: 3286832]

3. Batchelor T, Loeffler JS. Primary CNS lymphoma. J Clin Oncol. 2006; 24:1281-1288. [PubMed: 16525183]

4. Norden AD, Drappatz J, Wen PY, Claus EB. Survival among patients with primary central nervous system lymphoma, 1973-2004. J Neurooncol. 2011; 101:487-493. [PubMed: 20556477]

5. Ervin T, Canellos GP. Successful treatment of recurrent primary central nervous system lymphoma with high-dose methotrexate. Cancer. 1980; 45:1556-1557. [PubMed: 7370915]

6. Skarin AT, et al. High-dose methotrexate with folinic acid in the treatment of advanced non-Hodgkin lymphoma including CNS involvement. Blood. 1977; 50:1039-1047. [PubMed: 303529]

7. Illerhaus G, et al. High-dose chemotherapy and autologous stem-cell transplantation without consolidating radiotherapy as first-line treatment for primary lymphoma of the central nervous system. Haematologica. 2008; 93:147-148. [PubMed: 18166803]

8. Bromberg JE, et al. Central nervous system recurrence of systemic lymphoma in the era of stem cell transplantation - an International Primary Central Nervous System Lymphoma Study Group project. Haematologica. 2013; 98:808-813. [PubMed: 23144196]

9. Korfel A, et al. Phase II study of central nervous system (CNS)-directed chemotherapy including high-dose chemotherapy with autologous stem cell transplantation for CNS relapse of aggressive lymphomas. Haematologica. 2013; 98:364-370. [PubMed: 23242601]

10. Wieduwilt MJ, et al. Immunochemotherapy with intensive consolidation for primary CNS lymphoma: a pilot study and prognostic assessment by diffusion-weighted MRI. Clin Cancer Res. 2012; 18:1146-1155. [PubMed: 22228634]

11. Rubenstein JL, Gupta NK, Mannis GN, Lamarre AK, Treseler P. How I treat CNS lymphomas. Blood. 2013; 122:2318-2330. [PubMed: 23963042]

12. Rubenstein JL, et al. Intensive Chemotherapy and Immunotherapy in Patients With Newly Diagnosed Primary CNS Lymphoma: CALGB 50202 (Alliance 50202). J Clin Oncol. 2013; 31:3061-3068. [PubMed: 23569323]

13. Cingolani A, et al. Epstein-Barr virus infection is predictive of CNS involvement in systemic AIDS-related non-Hodgkin's lymphomas. J Clin Oncol. 2000; 18:3325-3330. [PubMed: 11013271] 
14. Schabet M. Epidemiology of primary CNS lymphoma. J Neurooncol. 1999; 43:199-201. [PubMed: 10563423]

15. Camilleri-Broet $\mathrm{S}$, et al. A uniform activated B-cell-like immunophenotype might explain the poor prognosis of primary central nervous system lymphomas: analysis of 83 cases. Blood. 2006; 107:190-196. [PubMed: 16150948]

16. Lai R, Rosenblum MK, DeAngelis LM. Primary CNS lymphoma: a whole-brain disease? Neurology. 2002; 59:1557-1562. [PubMed: 12451197]

17. Fine HA, Mayer RJ. Primary central nervous system lymphoma. Ann Intern Med. 1993; 119:10931104. [PubMed: 8239229]

18. McCann KJ, Ashton-Key M, Smith K, Stevenson FK, Ottensmeier CH. Primary central nervous system lymphoma: tumor-related clones exist in the blood and bone marrow with evidence for separate development. Blood. 2009; 113:4677-4680. [PubMed: 19096008]

19. Jahnke K, et al. Detection of subclinical systemic disease in primary CNS lymphoma by polymerase chain reaction of the rearranged immunoglobulin heavy-chain genes. J Clin Oncol. 2006; 24:4754-4757. [PubMed: 16966685]

20. Rubenstein JL, Treseler P, O’Brien JM. Pathology and genetics of primary central nervous system and intraocular lymphoma. Hematol Oncol Clin North Am. 2005; 19:705-717. vii. [PubMed: 16083831]

21. Shenkier TN, et al. Primary CNS lymphoma of T-cell origin: a descriptive analysis from the international primary CNS lymphoma collaborative group. J Clin Oncol. 2005; 23:2233-2239. [PubMed: 15800313]

22. Tu PH, et al. Clinicopathologic and genetic profile of intracranial marginal zone lymphoma: a primary low-grade CNS lymphoma that mimics meningioma. J Clin Oncol. 2005; 23:5718-5727. [PubMed: 16009945]

23. Braaten KM, et al. BCL-6 expression predicts improved survival in patients with primary central nervous system lymphoma. Clin Cancer Res. 2003; 9:1063-1069. [PubMed: 12631608]

24. Kreher S, et al. Prognostic impact of B-cell lymphoma 6 in primary CNS lymphoma. Neuro Oncol. 2015

25. Rubenstein JL, et al. Gene expression and angiotropism in primary CNS lymphoma. Blood. 2006; 107:3716-3723. [PubMed: 16418334]

26. Rubenstein JL, et al. Phase I study of intraventricular administration of rituximab in patients with recurrent CNS and intraocular lymphoma. J Clin Oncol. 2007; 25:1350-1356. [PubMed: 17312328]

27. Fischer L, et al. Differential micro-RNA expression in primary CNS and nodal diffuse large B-cell lymphomas. Neuro Oncol. 2011; 13:1090-1098. [PubMed: 21803762]

28. Baraniskin A, et al. Identification of microRNAs in the cerebrospinal fluid as marker for primary diffuse large B-cell lymphoma of the central nervous system. Blood. 2011; 117:3140-3146. [PubMed: 21200023]

29. Montesinos-Rongen M, Roost DV, Schaller C, Wiestler OD, Deckert M. Primary diffuse large Bcell lymphomas of the central nervous system are targeted by aberrant somatic hypermutation. Blood. 2004; 103:1869-1875. [PubMed: 14592832]

30. Montesinos-Rongen M, et al. Primary central nervous system lymphomas are derived from germinal-center B cells and show a preferential usage of the V4-34 gene segment. Am J Pathol. 1999; 155:2077-2086. [PubMed: 10595937]

31. Vater I, et al. The mutational pattern of primary lymphoma of the central nervous system determined by whole-exome sequencing. Leukemia. 2015; 29:677-685. [PubMed: 25189415]

32. Nakamura M, et al. Frequent alterations of the p14(ARF) and p16(INK4a) genes in primary central nervous system lymphomas. Cancer Res. 2001; 61:6335-6339. [PubMed: 11522621]

33. Kamijo T, Bodner S, van de Kamp E, Randle DH, Sherr CJ. Tumor spectrum in ARF-deficient mice. Cancer Res. 1999; 59:2217-2222. [PubMed: 10232611]

34. Nakamura M, Shimada K, Ishida E, Konishi N. Histopathology, pathogenesis and molecular genetics in primary central nervous system lymphomas. Histol Histopathol. 2004; 19:211-219. [PubMed: 14702189] 
35. Mrugala MM, Rubenstein JL, Ponzoni M, Batchelor TT. Insights into the biology of primary central nervous system lymphoma. Curr Oncol Rep. 2009; 11:73-80. [PubMed: 19080745]

36. Harada K, et al. Distinct primary central nervous system lymphoma defined by comparative genomic hybridization and laser scanning cytometry. Cancer Genet Cytogenet. 2001; 125:147150. [PubMed: 11369058]

37. Cady FM, et al. Del(6)(q22) and BCL6 rearrangements in primary CNS lymphoma are indicators of an aggressive clinical course. J Clin Oncol. 2008; 26:4814-4819. [PubMed: 18645192]

38. Harada K, Nishizaki T, Kubota H, Suzuki M, Sasaki K. Distinct primary central nervous system lymphoma defined by comparative genomic hybridization and laser scanning cytometry. Cancer Genet Cytogenet. 2001; 125:147-150. [PubMed: 11369058]

39. Boonstra R, Koning A, Mastik M, van den Berg A, Poppema S. Analysis of chromosomal copy number changes and oncoprotein expression in primary central nervous system lymphomas: frequent loss of chromosome arm 6q. Virchows Arch. 2003; 443:164-169. [PubMed: 12802586]

40. Weber $\mathrm{T}$, et al. Characteristic chromosomal imbalances in primary central nervous system lymphomas of the diffuse large B-cell type. Brain Pathol. 2000; 10:73-84. [PubMed: 10668897]

41. Courts C, et al. Recurrent inactivation of the PRDM1 gene in primary central nervous system lymphoma. J Neuropathol Exp Neurol. 2008; 67:720-727. [PubMed: 18596541]

42. Nakamura M, et al. Novel tumor suppressor loci on 6q22-23 in primary central nervous system lymphomas. Cancer Res. 2003; 63:737-741. [PubMed: 12591717]

43. Braggio E, et al. Primary central nervous system lymphomas: a validation study of array-based comparative genomic hybridization in formalin-fixed paraffin-embedded tumor specimens. Clin Cancer Res. 2011; 17:4245-4253. [PubMed: 21562036]

44. Schwindt $\mathrm{H}$, et al. Chromosomal imbalances and partial uniparental disomies in primary central nervous system lymphoma. Leukemia. 2009; 23:1875-1884. [PubMed: 19494841]

45. Montesinos-Rongen M, et al. Mutations of CARD11 but not TNFAIP3 may activate the NFkappaB pathway in primary CNS lymphoma. Acta Neuropathol. 2010; 120:529-535. [PubMed: 20544211]

46. Gonzalez-Aguilar A, et al. Recurrent mutations of MYD88 and TBL1XR1 in primary central nervous system lymphomas. Clin Cancer Res. 2012; 18:5203-5211. [PubMed: 22837180]

47. Montesinos-Rongen M, et al. Activating L265P mutations of the MYD88 gene are common in primary central nervous system lymphoma. Acta Neuropathol. 2011; 122:791-792. [PubMed: 22020631]

48. Roy S, et al. Protein biomarker identification in the CSF of patients with CNS lymphoma. J Clin Oncol. 2008; 26:96-105. [PubMed: 18056677]

49. Sasayama T, et al. Cerebrospinal fluid interleukin-10 is a potentially useful biomarker in immunocompetent primary central nervous system lymphoma (PCNSL). Neuro Oncol. 2012; 14:368-380. [PubMed: 22156547]

50. Rubenstein JL, et al. CXCL13 plus interleukin 10 is highly specific for the diagnosis of CNS lymphoma. Blood. 2013; 121:4740-4748. [PubMed: 23570798]

51. Sung CO, et al. Genomic profiling combined with gene expression profiling in primary central nervous system lymphoma. Blood. 2011; 117:1291-1300. [PubMed: 21088137]

52. Ngo VN, et al. Oncogenically active MYD88 mutations in human lymphoma. Nature. 2011; 470:115-119. [PubMed: 21179087]

53. Montesinos-Rongen M, Schafer E, Siebert R, Deckert M. Genes regulating the B cell receptor pathway are recurrently mutated in primary central nervous system lymphoma. Acta Neuropathol. 2012; 124:905-906. [PubMed: 23138649]

54. Fischer L, et al. CXCL13 and CXCL12 in central nervous system lymphoma patients. Clin Cancer Res. 2009; 15:5968-5973. [PubMed: 19773382]

55. Smith JR, et al. Expression of B-cell-attracting chemokine 1 (CXCL13) by malignant lymphocytes and vascular endothelium in primary central nervous system lymphoma. Blood. 2003; 101:815821. [PubMed: 12393412]

56. Smith JR, et al. Malignant B cells from patients with primary central nervous system lymphoma express stromal cell-derived factor-1. Am J Clin Pathol. 2007; 127:633-641. [PubMed: 17369141] 
57. Falkenhagen KM, Braziel RM, Fraunfelder FW, Smith JR. B-Cells in ocular adnexal lymphoproliferative lesions express B-cell attracting chemokine 1 (CXCL13). Am J Ophthalmol. 2005; 140:335-337. [PubMed: 16086967]

58. Ponzoni M, et al. Reactive perivascular T-cell infiltrate predicts survival in primary central nervous system B-cell lymphomas. Br J Haematol. 2007; 138:316-323. [PubMed: 17555470]

59. Kuker W, et al. Primary central nervous system lymphomas (PCNSL): MRI features at presentation in 100 patients. J Neurooncol. 2005; 72:169-177. [PubMed: 15925998]

60. Mabray MC, et al. Performance of Apparent Diffusion Coefficient Values and Conventional MRI Features in Differentiating Tumefactive Demyelinating Lesions From Primary Brain Neoplasms. AJR Am J Roentgenol. 2015; 205:1075-1085. [PubMed: 26496556]

61. Mabray MC, et al. The Combined Performance of ADC, CSF CXC Chemokine Ligand 13, and CSF Interleukin 10 in the Diagnosis of Central Nervous System Lymphoma. AJNR Am J Neuroradiol. 2016; 37:74-79. [PubMed: 26381553]

62. Valles FE, et al. Combined diffusion and perfusion MR imaging as biomarkers of prognosis in immunocompetent patients with primary central nervous system lymphoma. AJNR Am J Neuroradiol. 2013; 34:35-40. [PubMed: 22936096]

63. Barajas RF Jr, Rubenstein JL, Chang JS, Hwang J, Cha S. Diffusion-weighted MR imaging derived apparent diffusion coefficient is predictive of clinical outcome in primary central nervous system lymphoma. AJNR Am J Neuroradiol. 2010; 31:60-66. [PubMed: 19729544]

64. Fischer L, et al. Non-enhancing relapse of a primary CNS lymphoma with multiple diffusionrestricted lesions. J Neurooncol. 2011; 102:163-166. [PubMed: 20602148]

65. Reiche W, Hagen T, Schuchardt V, Billmann P. Diffusion-weighted MR imaging improves diagnosis of CNS lymphomas. A report of four cases with common and uncommon imaging features. Clin Neurol Neurosurg. 2007; 109:92-101. [PubMed: 16644103]

66. Porter AB, et al. Primary central nervous system lymphoma can be histologically diagnosed after previous corticosteroid use: a pilot study to determine whether corticosteroids prevent the diagnosis of primary central nervous system lymphoma. Ann Neurol. 2008; 63:662-667. [PubMed: 18481293]

67. Pirotte B, et al. Glucocorticoid-induced long-term remission in primary cerebral lymphoma: case report and review of the literature. J Neurooncol. 1997; 32:63-69. [PubMed: 9049864]

68. Bonzheim I, et al. High frequency of MYD88 mutations in vitreoretinal B-cell lymphoma: a valuable tool to improve diagnostic yield of vitreous aspirates. Blood. 2015; 126:76-79. [PubMed: 25900979]

69. Chan CC, Buggage RR, Nussenblatt RB. Intraocular lymphoma. Curr Opin Ophthalmol. 2002; 13:411-418. [PubMed: 12441846]

70. Mohile NA, Deangelis LM, Abrey LE. The utility of body FDG PET in staging primary central nervous system lymphoma. Neuro Oncol. 2008; 10:223-228. [PubMed: 18287338]

71. Ferreri AJ, et al. Prognostic scoring system for primary CNS lymphomas: the International Extranodal Lymphoma Study Group experience. J Clin Oncol. 2003; 21:266-272. [PubMed: 12525518]

72. Abrey LE, et al. Primary central nervous system lymphoma: the Memorial Sloan-Kettering Cancer Center prognostic model. J Clin Oncol. 2006; 24:5711-5715. [PubMed: 17116938]

73. DeAngelis LM, et al. Primary CNS lymphoma: combined treatment with chemotherapy and radiotherapy. Neurology. 1990; 40:80-86. [PubMed: 2296388]

74. Bataille B, et al. Primary intracerebral malignant lymphoma: report of 248 cases. J Neurosurg. 2000; 92:261-266. [PubMed: 10659013]

75. Weller M, Martus P, Roth P, Thiel E, Korfel A. Surgery for primary CNS lymphoma? Challenging a paradigm. Neuro Oncol. 2012; 14:1481-1484. [PubMed: 22984018]

76. Nelson DF, et al. Non-Hodgkin's lymphoma of the brain: can high dose, large volume radiation therapy improve survival? Report on a prospective trial by the Radiation Therapy Oncology Group (RTOG): RTOG 8315. Int J Radiat Oncol Biol Phys. 1992; 23:9-17. [PubMed: 1572835]

77. Abrey LE, DeAngelis LM, Yahalom J. Long-term survival in primary CNS lymphoma. J Clin Oncol. 1998; 16:859-863. [PubMed: 9508166] 
78. Correa DD, et al. Prospective cognitive follow-up in primary CNS lymphoma patients treated with chemotherapy and reduced-dose radiotherapy. J Neurooncol. 2009; 91:315-321. [PubMed: 18974934]

79. Sun A, et al. Phase III trial of prophylactic cranial irradiation compared with observation in patients with locally advanced non-small-cell lung cancer: neurocognitive and quality-of-life analysis. J Clin Oncol. 2011; 29:279-286. [PubMed: 21135267]

80. Morris PG, et al. Rituximab, methotrexate, procarbazine, and vincristine followed by consolidation reduced-dose whole-brain radiotherapy and cytarabine in newly diagnosed primary CNS lymphoma: final results and long-term outcome. J Clin Oncol. 2013; 31:3971-3979. [PubMed: 24101038]

81. Blay JY, et al. High-dose methotrexate for the treatment of primary cerebral lymphomas: analysis of survival and late neurologic toxicity in a retrospective series. J Clin Oncol. 1998; 16:864-871. [PubMed: 9508167]

82. Glantz MJ, et al. High-dose intravenous methotrexate for patients with nonleukemic leptomeningeal cancer: is intrathecal chemotherapy necessary? J Clin Oncol. 1998; 16:1561-1567. [PubMed: 9552066]

83. Khan RB, Shi W, Thaler HT, DeAngelis LM, Abrey LE. Is intrathecal methotrexate necessary in the treatment of primary CNS lymphoma? J Neurooncol. 2002; 58:175-178. [PubMed: 12164690]

84. Schwartz S, et al. Glucarpidase (carboxypeptidase g2) intervention in adult and elderly cancer patients with renal dysfunction and delayed methotrexate elimination after high-dose methotrexate therapy. Oncologist. 2007; 12:1299-1308. [PubMed: 18055849]

85. DeAngelis LM, Seiferheld W, Schold SC, Fisher B, Schultz CJ. Combination chemotherapy and radiotherapy for primary central nervous system lymphoma: Radiation Therapy Oncology Group Study 93-10. J Clin Oncol. 2002; 20:4643-4648. [PubMed: 12488408]

86. DeAngelis LM, Yahalom J, Thaler HT, Kher U. Combined modality therapy for primary CNS lymphoma. J Clin Oncol. 1992; 10:635-643. [PubMed: 1548527]

87. Glass J, Gruber ML, Cher L, Hochberg FH. Preirradiation methotrexate chemotherapy of primary central nervous system lymphoma: long-term outcome. J Neurosurg. 1994; 81:188-195. [PubMed: 8027800]

88. Thiel E, et al. High-dose methotrexate with or without whole brain radiotherapy for primary CNS lymphoma (G-PCNSL-SG-1): a phase 3, randomised, non-inferiority trial. Lancet Oncol. 2010; 11:1036-1047. [PubMed: 20970380]

89. Abrey LE, et al. High-dose chemotherapy with stem cell rescue as initial therapy for anaplastic oligodendroglioma. J Neurooncol. 2003; 65:127-134. [PubMed: 14686732]

90. Soussain C, et al. Results of intensive chemotherapy followed by hematopoietic stem-cell rescue in 22 patients with refractory or recurrent primary CNS lymphoma or intraocular lymphoma. J Clin Oncol. 2001; 19:742-749. [PubMed: 11157026]

91. Ott RJ, et al. Measurements of blood-brain barrier permeability in patients undergoing radiotherapy and chemotherapy for primary cerebral lymphoma. Eur J Cancer. 1991; 27:1356-1361. [PubMed: 1835848]

92. Reni M, Ferreri AJ, Landoni C, Villa E. Salvage therapy with temozolomide in an immunocompetent patient with primary brain lymphoma. J Natl Cancer Inst. 2000; 92:575-576. [PubMed: 10749917]

93. Reni M, et al. Temozolomide as salvage treatment in primary brain lymphomas. Br J Cancer. 2007; 96:864-867. [PubMed: 17325700]

94. Wong ET, Tishler R, Barron L, Wu JK. Immunochemotherapy with rituximab and temozolomide for central nervous system lymphomas. Cancer. 2004; 101:139-145. [PubMed: 15221999]

95. Osoba D, Brada M, Yung WK, Prados MD. Health-related quality of life in patients with anaplastic astrocytoma during treatment with temozolomide. Eur J Cancer. 2000; 36:1788-1795. [PubMed: 10974627]

96. Osoba D, Brada M, Yung WK, Prados M. Health-related quality of life in patients treated with temozolomide versus procarbazine for recurrent glioblastoma multiforme. J Clin Oncol. 2000; 18:1481-1491. [PubMed: 10735896] 
97. Damon LE, et al. Immunochemotherapy and autologous stem-cell transplantation for untreated patients with mantle-cell lymphoma: CALGB 59909. J Clin Oncol. 2009; 27:6101-6108. [PubMed: 19917845]

98. Damon L, et al. Impact of intensive PBSC mobilization therapy on outcomes following auto-SCT for non-Hodgkin's lymphoma. Bone Marrow Transplant. 2008; 42:649-657. [PubMed: 18679366]

99. Linker CA, et al. Auto-SCT for AML in second remission: CALGB study 9620. Bone Marrow Transplant. 2009; 44:353-359. [PubMed: 19289999]

100. Wilson WH, et al. EPOCH chemotherapy: toxicity and efficacy in relapsed and refractory nonHodgkin's lymphoma. J Clin Oncol. 1993; 11:1573-1582. [PubMed: 7687667]

101. Wilson WH, et al. Phase II study of dose-adjusted EPOCH and rituximab in untreated diffuse large B-cell lymphoma with analysis of germinal center and post-germinal center biomarkers. J Clin Oncol. 2008; 26:2717-2724. [PubMed: 18378569]

102. Relling MV, et al. Etoposide achieves potentially cytotoxic concentrations in CSF of children with acute lymphoblastic leukemia. J Clin Oncol. 1996; 14:399-404. [PubMed: 8636749]

103. Boehme V, et al. Incidence and risk factors of central nervous system recurrence in aggressive lymphoma--a survey of 1693 patients treated in protocols of the German High-Grade NonHodgkin's Lymphoma Study Group (DSHNHL). Ann Oncol. 2007; 18:149-157. [PubMed: 17018708]

104. Batchelor TT, et al. Rituximab monotherapy for patients with recurrent primary CNS lymphoma. Neurology. 2011; 76:929-930. [PubMed: 21383331]

105. Omuro A, et al. R-MPV followed by high-dose chemotherapy with TBC and autologous stem-cell transplant for newly diagnosed primary CNS lymphoma. Blood. 2015; 125:1403-1410. [PubMed: 25568347]

106. Omuro A, et al. Methotrexate and temozolomide versus methotrexate, procarbazine, vincristine, and cytarabine for primary CNS lymphoma in an elderly population: an intergroup ANOCEFGOELAMS randomised phase 2 trial. Lancet Haematol. 2015; 2:e251-259. [PubMed: 26688235]

107. Correa DD, et al. Cognitive functions in primary CNS lymphoma after single or combined modality regimens. Neuro Oncol. 2012; 14:101-108. [PubMed: 22013168]

108. Soussain C, et al. Intensive chemotherapy followed by hematopoietic stem-cell rescue for refractory and recurrent primary CNS and intraocular lymphoma: Societe Francaise de Greffe de Moelle Osseuse-Therapie Cellulaire. J Clin Oncol. 2008; 26:2512-2518. [PubMed: 18413641]

109. Cote GM, et al. Autologous stem cell transplantation with thiotepa, busulfan, and cyclophosphamide (TBC) conditioning in patients with CNS involvement by non-Hodgkin lymphoma. Biol Blood Marrow Transplant. 2012; 18:76-83. [PubMed: 21749848]

110. Falzetti F, et al. High-dose thiotepa, etoposide and carboplatin as conditioning regimen for autologous stem cell transplantation in patients with high-risk non-Hodgkin lymphoma. Clin Exp Med. 2012; 12:165-171. [PubMed: 21928053]

111. Alvarnas JC, et al. High-dose therapy with hematopoietic cell transplantation for patients with central nervous system involvement by non-Hodgkin's lymphoma. Biol Blood Marrow Transplant. 2000; 6:352-358. [PubMed: 10905773]

112. Raizer JJ, et al. Pemetrexed in the treatment of relapsed/refractory primary central nervous system lymphoma. Cancer. 2012; 118:3743-3748. [PubMed: 22179954]

113. Feugier $P$, et al. Incidence and risk factors for central nervous system occurrence in elderly patients with diffuse large-B-cell lymphoma: influence of rituximab. Ann Oncol. 2004; 15:129133. [PubMed: 14679132]

114. Tai WM, et al. Central nervous system (CNS) relapse in diffuse large B cell lymphoma (DLBCL): pre- and post-rituximab. Ann Hematol. 2011; 90:809-818. [PubMed: 21229246]

115. Yamamoto W, et al. Central nervous system involvement in diffuse large B-cell lymphoma. Eur J Haematol. 2010; 85:6-10. [PubMed: 20236301]

116. Rubenstein JL, et al. Multicenter phase 1 trial of intraventricular immunochemotherapy in recurrent CNS lymphoma. Blood. 2013; 121:745-751. [PubMed: 23197589]

117. Kadoch C, et al. Complement activation and intraventricular rituximab distribution in recurrent central nervous system lymphoma. Clin Cancer Res. 2014; 20:1029-1041. [PubMed: 24190981] 
118. Shah GD, et al. Combined immunochemotherapy with reduced whole-brain radiotherapy for newly diagnosed primary CNS lymphoma. J Clin Oncol. 2007; 25:4730-4735. [PubMed: 17947720]

119. Berenbom A, Davila RM, Lin HS, Harbour JW. Treatment outcomes for primary intraocular lymphoma: implications for external beam radiotherapy. Eye (Lond). 2007; 21:1198-1201. [PubMed: 16732210]

120. Kitzmann AS, et al. Intraocular use of rituximab. Eye (Lond). 2007; 21:1524-1527. [PubMed: 17464308]

121. Itty S, Pulido JS. Rituximab for intraocular lymphoma. Retina. 2009; 29:129-132. [PubMed: 19202422]

122. Chan CC, et al. Primary vitreoretinal lymphoma: a report from an International Primary Central Nervous System Lymphoma Collaborative Group symposium. Oncologist. 2011; 16:1589-1599. [PubMed: 22045784]

123. Batchelor TT, Kolak G, Ciordia R, Foster CS, Henson JW. High-dose methotrexate for intraocular lymphoma. Clin Cancer Res. 2003; 9:711-715. [PubMed: 12576439]

124. Jahnke K, et al. Ifosfamide or trofosfamide in patients with intraocular lymphoma. J Neurooncol. 2009; 93:213-217. [PubMed: 19099202]

125. Cheah CY, et al. Intensive chemoimmunotherapy and bilateral globe irradiation as initial therapy for primary intraocular lymphoma. Neuro Oncol. 2016; 18:575-581. [PubMed: 26487691]

126. Stefanovic A, Davis J, Murray T, Markoe A, Lossos IS. Treatment of isolated primary intraocular lymphoma with high-dose methotrexate-based chemotherapy and binocular radiation therapy: a single-institution experience. Br J Haematol. 2010; 151:103-106. [PubMed: 20629657]

127. Jacomet $\mathrm{C}$, et al. Intravenous methotrexate for primary central nervous system non-Hodgkin's lymphoma in AIDS. AIDS. 1997; 11:1725-1730. [PubMed: 9386807]

128. Elstrom RL, et al. Treatment of PTLD with rituximab or chemotherapy. Am J Transplant. 2006; 6:569-576. [PubMed: 16468968]

129. van de Glind G, et al. Intrathecal rituximab treatment for pediatric post-transplant lymphoproliferative disorder of the central nervous system. Pediatr Blood Cancer. 2008; 50:886888. [PubMed: 17668865]

130. Wang CC, Carnevale J, Rubenstein JL. Progress in central nervous system lymphomas. Br J Haematol. 2014; 166:311-325. [PubMed: 24837460]

131. Hagner PR, et al. CC-122, a pleiotropic pathway modifier, mimics an interferon response and has antitumor activity in DLBCL. Blood. 2015; 126:779-789. [PubMed: 26002965]

132. Ponzoni M, Issa S, Batchelor TT, Rubenstein JL. Beyond high-dose methotrexate and brain radiotherapy: novel targets and agents for primary CNS lymphoma. Ann Oncol. 2014; 25:316322. [PubMed: 24265352]

133. Fraser E, Gruenberg K, Rubenstein JL. New approaches in primary central nervous system lymphoma. Chin Clin Oncol. 2015; 4:11. [PubMed: 25841718] 


\section{Key Points}

1. Long-term survival and cure is feasible in primary CNS lymphoma (PCNSL) without whole brain radiotherapy.

2. Whole brain radiotherapy consolidation is associated with severe neurotoxicity, particularly in patients older than 60 .

3. High-dose chemotherapy is currently under investigation as first-line consolidation.

4. There is a need for novel therapies that target key survival pathways in PCNSL, including activation of NF-kB survival signaling. 


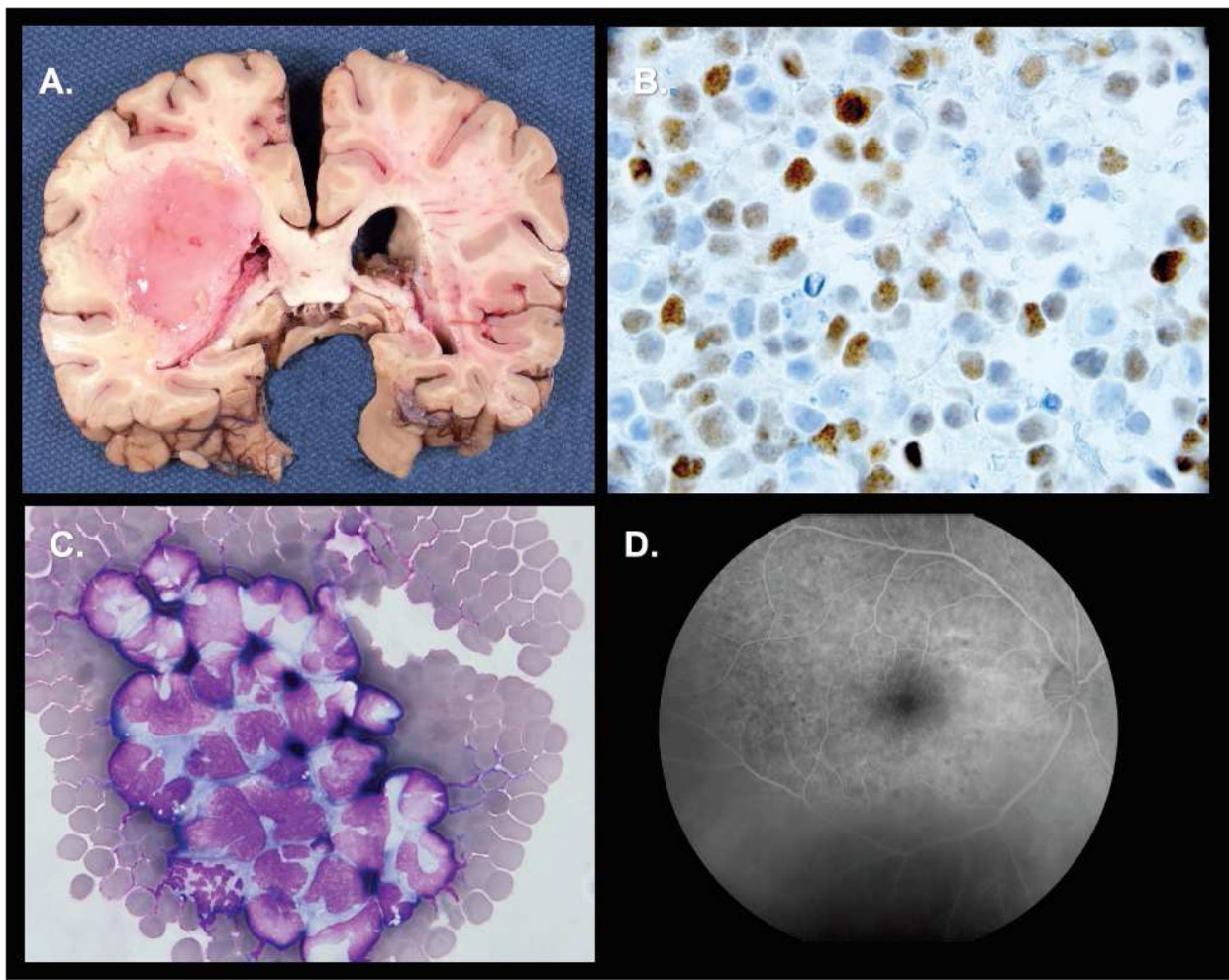

Figure 1.

Pathologic features of PCNSL. (A) Diffuse, large B-cell lymphoma (DLBCL) involving the left parietal lobe and basal ganglia with significant mass effect, subependymal spread, and invasion of the lateral ventricle, upon progression with HD-MTX and rituximab-based chemotherapy. (B) High expression of MUM1 by diffuse large B-cell lymphoma cells in a diagnostic specimen of PCNSL, as demonstrated by immunohistochemistry (B) Cytology of diffuse large B-cell lymphoma in cerebrospinal fluid in recurrent PCNSL. (C) Fluorescein angiography demonstrates classic 'leopard spots' in intraocular lymphoma. (Courtesy of Ray Sobel, MD, Stanford University School of Medicine, Stanford, CA.) 


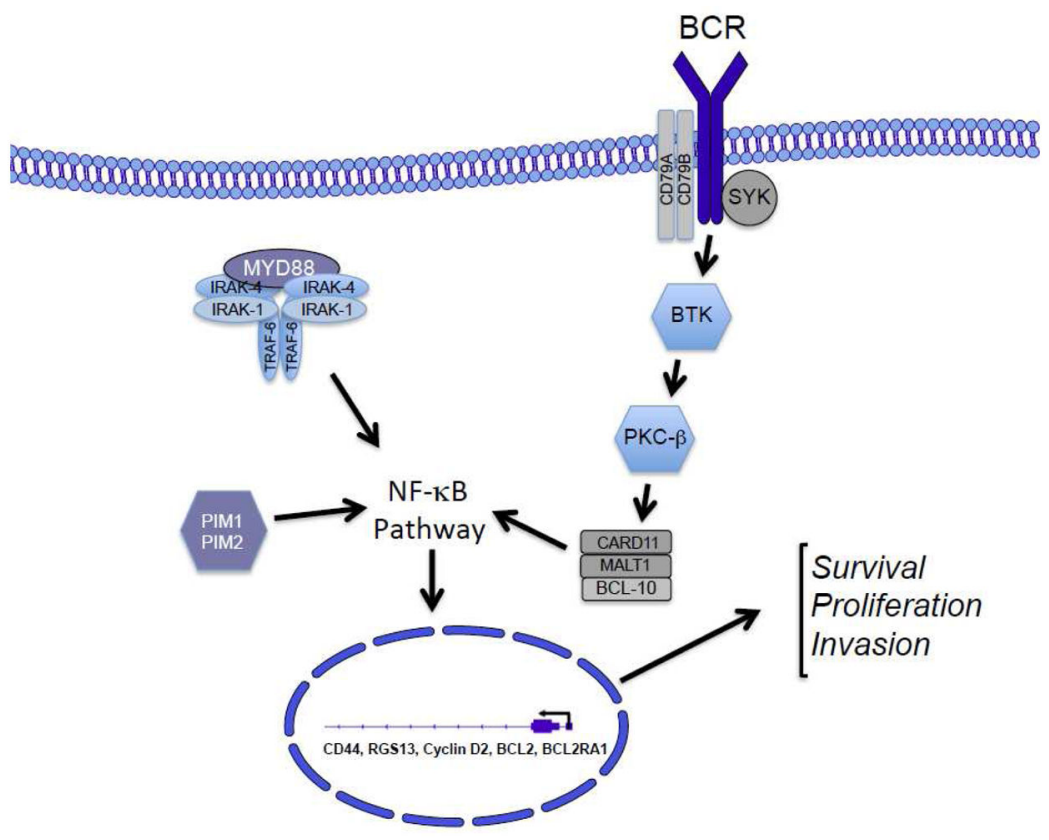

Figure 2. NF-kB Activation in Primary CNS Lymphoma

NF-kB transcriptional activation is regulated by multiple signals in PCNSL, including the MYD88/IRAK1/4 complex and the B cell receptor (BCR) complex consisting of CD79A and B and SYK tyrosine kinase. Activation of IRAK1 and 4 kinases via the oncogenic mutation of MYD88 at L265P impacts $~ 50 \%$ of PCNSL cases. MYD88 is an adapter protein that mediates toll-like receptor (TLR) and interleukin-1 receptor signaling. In addition, chronic active signaling via the BCR involving SYK and BTK also potentiates NF-kB activation. Activating mutations involving CD79B, a component of the BCR, as well as CARD11, a mediator of BCR signaling, are each present in $\sim 15 \%$ of cases and result in NF$\mathrm{kB}$ activation. 

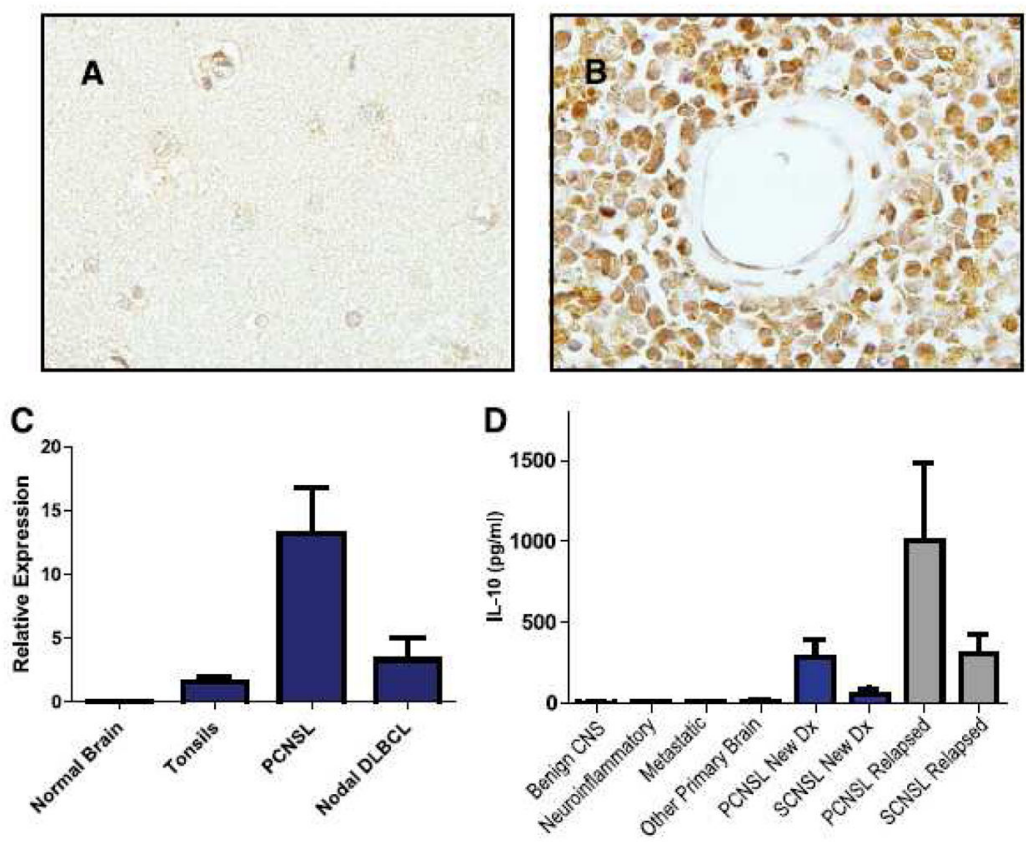

Figure 3.

IL-10 Expression in CNS Lymphomas. Absent expression in normal brain (A) with strong expression of IL-10 by lymphoma cells in PCNSL (B), as demonstrated by immunohistochemistry. (X1000). (C) Quantitative RT-PCR demonstrates markedly increased expression of IL-10 in diagnostic specimens of PCNSL ( $N=23$ ) compared with reactive tonsils and normal brain. The average IL-10 expression was higher in PCNSL compared to 9 cases of nodal DLBCL of which 7 were of germinal center phenotype. (D) Mean CSF IL-10 protein is 70-fold higher in patients with PCNSL and SCNSL compared to neuro-inflammatory conditions and other brain tumors $\left(\mathrm{p}<2.3 \times 10^{-5}\right)$. CSF concentration of IL-10 was highest in relapsed cases. 


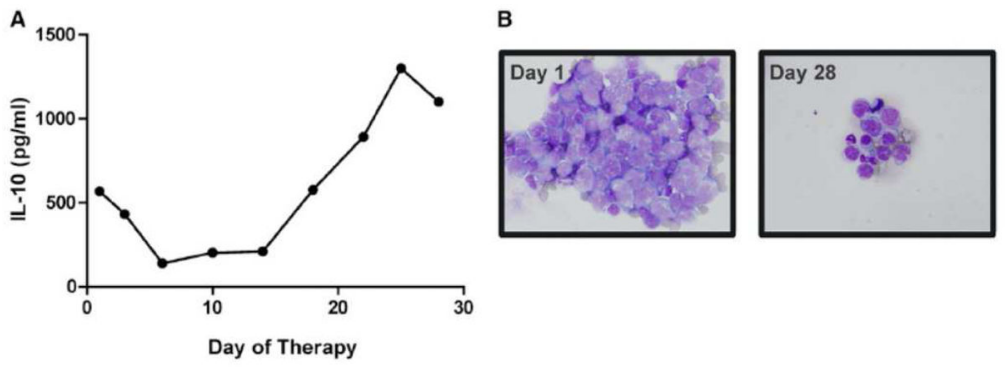

Figure 4.

(A) IL-10 concentration in CSF correlates with disease course in patients with recurrent CNS lymphomas that are treated with rituximab plus methotrexate (representative of six consecutive cases). (B) Cytological appearance of lymphoma cells in CSF at baseline and persistent disease at completion of intraventricular therapy with rituximab plus methotrexate. (From Rubenstein, J.L., et al. CXCL13 plus interleukin 10 is highly specific for the diagnosis of CNS lymphoma. Blood 2013;121:4740-4748; with permission.) 


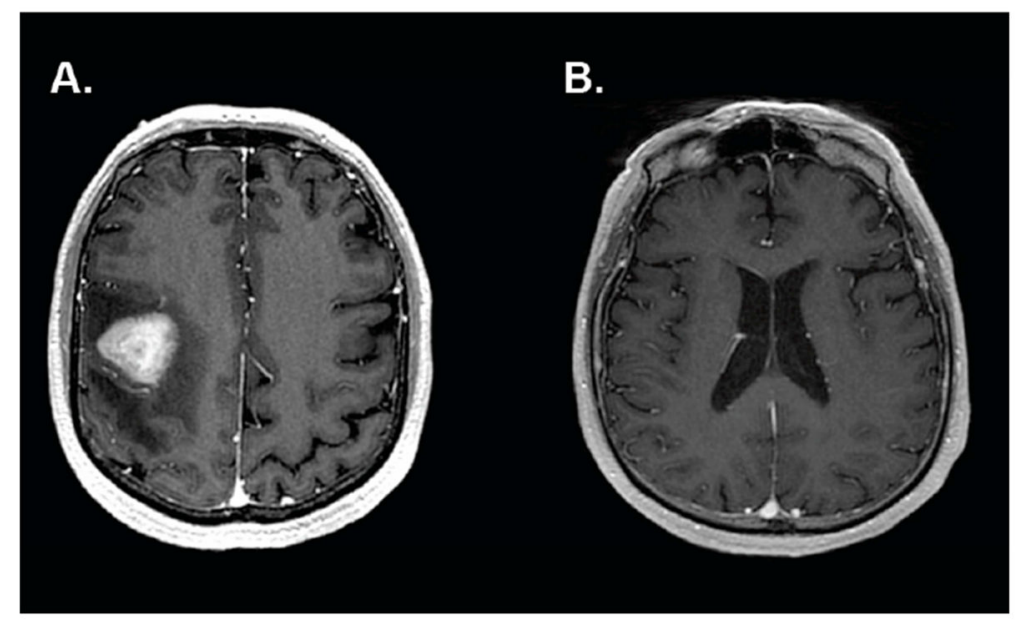

Figure 5.

MRI features of PCNSL in two patients at diagnosis (A). MRI depicts homogeneously enhancing mass with vasogeneic edema. (B). Normal appearing MRI of patient with progressive neurologic symptoms who was aggressively treated with steroids before a diagnosis could be elicited. Four repeat CSF collections and one brain biopsy were nondiagnostic and the diagnosis of disseminated PCNSL was made at autopsy. Notably, the CSF of each patient contained elevated concentrations of CXCL13 and IL-10, highly specific biomarkers that facilitate diagnosis of PCNSL. (From Rubenstein, J.L., et al. CXCL13 plus interleukin 10 is highly specific for the diagnosis of CNS lymphoma. Blood 2013;121:47404748; with permission.) 
A.

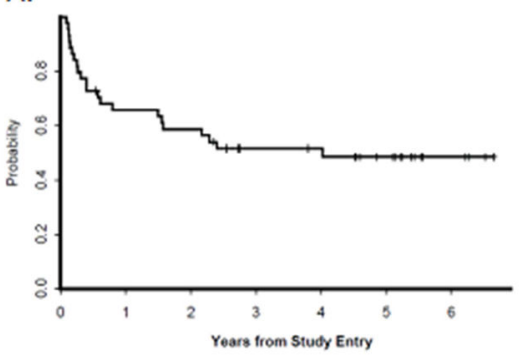

C.

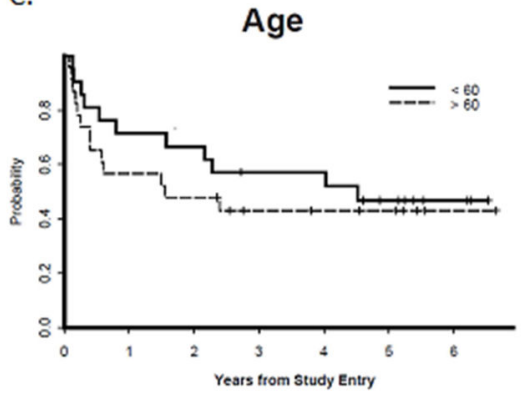

B.

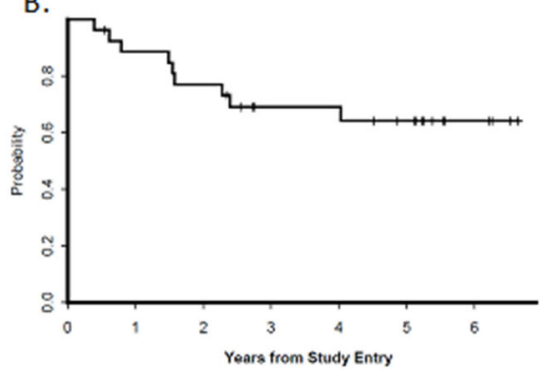

D.

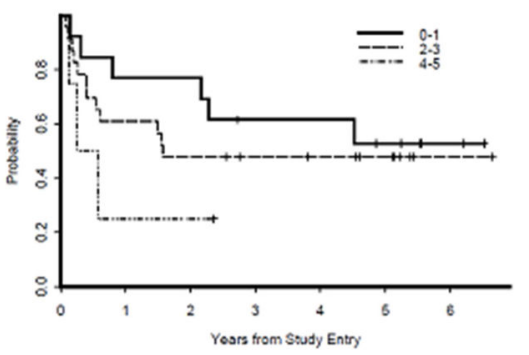

Figure 6. Outcomes with intensive chemotherapy and immunotherapy in newly-diagnosed primary central nervous system lymphoma, without whole brain radiotherapy: CALGB (Alliance) 50202)

Outcome for all CALGB 50202 patients; y-axis refers to cumulative probability of event. (A) Progression-free survival (PFS) for all patients. The 2-year PFS was 59\%. (B) PFS for those patients who attained a complete response with MT- R (high-dose methotrexate, temozolomide, rituximab) induction and received EA (etoposide cytararbine) consolidation $(\mathrm{n}=27)$. (C) PFS was similar for patients aged $>60$ years $(\mathrm{n}=23)$ and for younger patients $\left(\mathrm{n}=21 ; \mathrm{P}=0 \_48\right)$. (D) There was a trend between shorter PFS and highest International Extranodal Lymphoma Study Group (IELSG) risk score of 4-5 (P=0_16). (From Rubenstein JL, Hsi ED, Johnson JL, Jung SH, Nakashima MO, Grant B, Cheson BD \& Kaplan LD. Intensive Chemotherapy and Immunotherapy in Patients With Newly Diagnosed Primary CNS Lymphoma: CALGB 50202 (Alliance 50202). J Clin Oncol 31 (2013), 30613068; with permission.) 


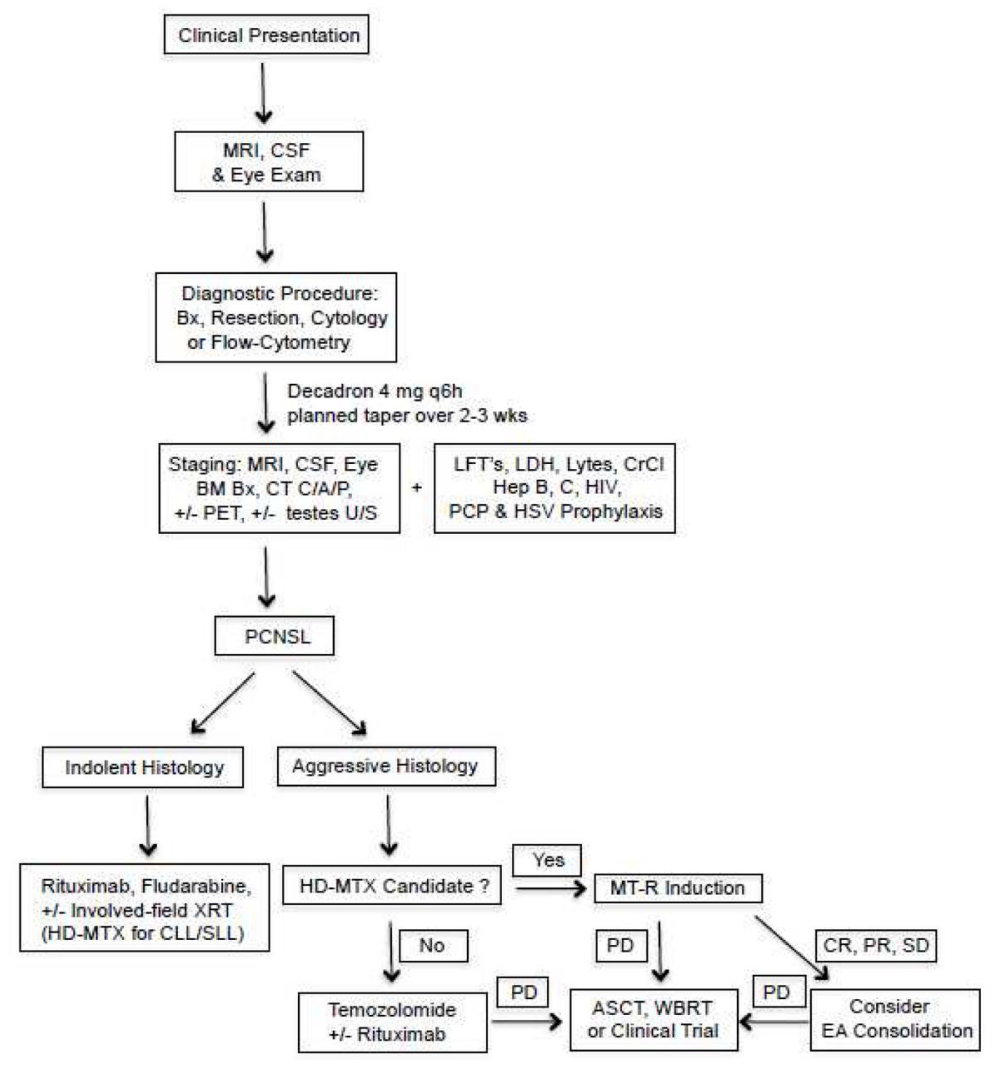

Figure 7. Approach to Treatment of Newly Diagnosed Primary CNS Lymphoma

In the diagnostic work-up, an MRI of the spine may be useful if warranted by neurologic symptoms or if CSF analysis is contraindicated. Ultrasonography of the testes is indicated for older male patients with CNS involvement of lymphoma in which testes coinvolvement is suspected on clinical and/or radiographic grounds. The value of a positron emission tomography scan in this setting is not established. Although the schedule of Decadron taper should be individualized, we recommend a planned taper to be completed within 2 to 3 weeks of diagnosis, between the first and second courses of HD-MTX. Therapeutic options for indolent lymphomas that involve the CNS or dura include rituximab, fludarabine, involved-field irradiation, and HD-MTX for CNS involvement of chronic lymphocytic leukemia/small lymphocytic leukemia. For newly diagnosed patients who are not candidates for HD-MTX, in most cases we recommend a trial of temozolomide and rituximab and/or strategies that use high-dose chemotherapy, before consideration of using whole-brain irradiation. ASCT, autologous stem cell transplant; CR, complete response; EA, etoposidecytarabine; HSV, herpes simplex virus; MT-R, combination HD-MTX, temozolomide, and rituximab (rituximab is omitted for T-cell lymphomas); PCP, Pneumocytis jiroveci pneumonia; PD, progressive disease; PR, partial response; SD, stable disease; WBRT, whole-brain radiotherapy. (Originally published by the American Society of Hematology. (From Rubenstein et al., How I treat CNS lymphomas. Blood 20134;122:2318-2330; with permission.) 


\section{Table 1}

Regimens that are active in Dose Intensive Consolidation and Myeloablative Therapy in CNS Lymphomas.

\begin{tabular}{|l|l|}
\hline Intensive Consolidation/Preparative Regimen & Reference \\
\hline Carmustine, Thiotepa, Etoposide & Korfel (2013) \\
\hline Infusional Etoposide, High-Dose Cytarabine & Wieduwilt (2012); Rubenstein (2013b) \\
\hline Thiotepa, Busulfan, Cyclophosphamide & Soussain (2002, 2008); Cote (2012), Omuro (2015) \\
\hline Carmustine, Thiotepa & Illerhaus (2008) \\
\hline Cyclophosphamide, Carmustine, Etoposide & Alvarnas (2000) \\
\hline
\end{tabular}

